\title{
Staphylococcal Enterotoxin B
}

National Cancer Institute

\section{Source}

National Cancer Institute. Staphylococcal Enterotoxin B. NCI Thesaurus. Code C1084.

\begin{abstract}
A bacterial enterotoxin with potential immunostimulatory activity. Staphylococcal enterotoxin B (SEB), a gram positive superantigen produced by Staphylococcus aureus, is a potent stimulator of T-cell activation. SEB binds directly to class II major histocompatibility complex $(\mathrm{MHC})$ molecules and the $\mathrm{V}$ beta region of the $\mathrm{T}$-cell receptor (TCR), leading to an amplified T-cell response. In response to SEB, both CD4+ and CD8+ cells proliferate, secrete cytokines and demonstrate enhanced cytotoxic activity against a broad range of antigens. Co-administration of SEB with interleukin-2 (IL-2) by direct injection into tumor cells, may induce clonal T-cell expansion and potentiate apoptosis of tumor cells, resulting in decreased tumor growth.
\end{abstract}

